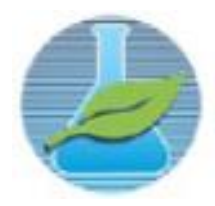

JCEC/REQ ${ }^{2}$

Journal

ISSN: 2446-9416

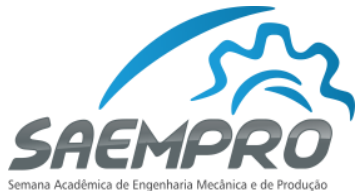

"EU, A INDÚSTRIA E O MUNDO"

08 a 11 de novembro de 2016 no campus Viçosa da UFV

Departamento de Engenharia de Produção e Mecânica - DEP

Universidade Federal de Viçosa - UFV

\title{
PROJETO DE GESTÃO POR COMPETÊNCIAS DA ÁREA TÉCNICA DO NEMOS
}

\author{
Fabiana Raimunda Rocha Batista, Alexandre Navarro da Silva, Álvaro Messias Bigonha \\ Tibiriçá, Danielle Dias Sant'Anna Martins
}

Universidade Federal de Viçosa, Departamento de Engenharia de Produção e Mecânica

Ph. Rolfs s/n - 36570-000 - Viçosa - MG

fabianarocharb@gmail.com

\section{INTRODUÇÃ̃O}

As organizações progressivamente têm percebido a importância de investirem no desenvolvimento de seu ativo humano, como forma de atingirem seus objetivos e propiciarem a melhoria contínua de seus resultados.

Neste cenário, é importante destacar que um grande número de programas e/ou projetos estudantis é abrigado em graduações de engenharia em universidades de todo o país. No entanto, a forma de gerir essas equipes visando aumentar a produtividade e a qualidade dos projetos desenvolvidos ainda é muito pouco estudada. Na formação do estudante de graduação é importante o aprendizado vivencial de trabalho e de gestão em equipes. Logo, o uso de técnicas de gestão para gerenciar equipes possui a máxima relevância nos dias atuais.

Neste contexto, percebeu-se a oportunidade de implantar um modelo de gestão por competências na área técnica do NEMOS (Núcleo de Engenharia de Modelagem e Simulação), projeto vinculado ao Departamento de Engenharia de Produção e Mecânica da Universidade Federal de Viçosa, como forma de otimização de seus resultados.

\section{OBJETIVOS}

O presente estudo teve como foco a elaboração de um projeto de implantação da gestão por competências na área técnica do NEMOS, a partir da identificação de ferramentas de auxílio ao desenvolvimento de pessoas, as quais tem como objetivo facilitar a obtenção e análise de dados para a gestão dos recursos humanos.

\section{METODOLOGIA}

A Metodologia utilizada foi a pesquisa-ação, além da realização de benchmarking com outras organizações.

\section{RESULTADOS}

O projeto de implantação da Gestão por Competências no NEMOS, iniciou-se por meio da análise do mapa de processos da área técnica (Fig.1), que apresenta todas as etapas necessárias para o desenvolvimento de um artigo científico, seu produto final. 


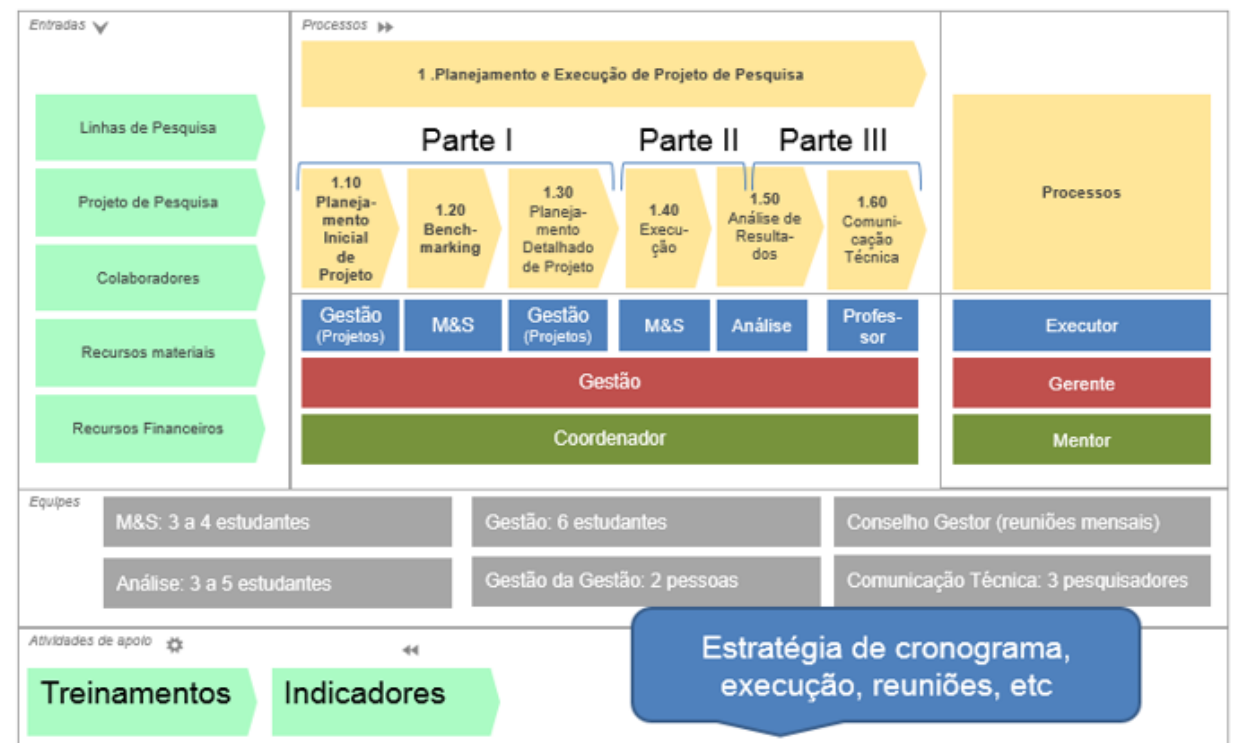

Figura 1 - Etapas de desenvolvimento de um projeto científico.

Como resultado da pesquisa, tem-se o desenvolvimento das ferramentas, descritas a seguir.

\section{* Mapeamento do Perfil de Competências}

Através do mapeamento de competências, realizado com base nos indicadores (atividades do mapa de processos), foi possível compilar todas as competências técnicas e comportamentais, necessárias para a realização de cada atividade, conforme Tab. 1. Posteriormente, tais competências foram agrupadas por função, identificando o perfil de competências necessário para o desempenho das atividades de cada função, como mostrado na Tab. 2.

Tabela 1 - Mapeamento de Competências

\begin{tabular}{|c|c|c|}
\hline \multirow{2}{*}{$\begin{array}{c}\text { ETAPAS DO } \\
\text { PLANEJAMENTOE } \\
\text { EXECUÇÃOO DO PROJETO DE } \\
\text { PESQUISA }\end{array}$} & \multicolumn{2}{|c|}{ COMPETÊNCIAS } \\
\hline & COMPETÊNCIAS TÉCNICAS & COMPETÊNCIAS COMPORTAMENTAIS \\
\hline \multicolumn{3}{|l|}{$\begin{array}{l}\text { 1.1-PLANEAMMENTO } \\
\text { INICIAL DO PROJETO }\end{array}$} \\
\hline $\begin{array}{l}\text { Preenchimento de } \\
\text { formulário }\end{array}$ & $\begin{array}{l}\text { "Coordenadores: } \\
\text {-Conhecimento específico na } \\
\text { área de projeto, } \\
\text {-Atualização sobre a área. }\end{array}$ & $\begin{array}{l}\text {-Objetividade, } \\
\text {-Estratégia }\end{array}$ \\
\hline $\begin{array}{l}\text { Discussão de planejamento } \\
\text { no âmbito do NEMOS }\end{array}$ & $\begin{array}{l}\text { "Coordenadores: } \\
\text {-Conhecimento específico na } \\
\text { área de projeto, } \\
\text {-Atualização sobre a área, } \\
\text { "Gestão: } \\
\text { - Técnicas de apresentação e } \\
\text { power point. }\end{array}$ & \begin{tabular}{|l}
-Visão sistêmica, \\
-Clareza, \\
- Comunicação oral, \\
-Organizaçẫo, \\
-Capacidade de sintese, \\
- Tomada de decisão
\end{tabular} \\
\hline $\begin{array}{l}\text { Construir cronograma } \\
\text { inicial (macro) }\end{array}$ & $\begin{array}{l}\text { "Gestão: } \\
\text {-Project, } \\
\text {-Conhecimento técnico em } \\
\text { gestão de projetos. }\end{array}$ & $\begin{array}{l}\text {-Planejamento, } \\
\text {-Visão sistêmica, } \\
\text {-Organização }\end{array}$ \\
\hline \multicolumn{3}{|l|}{ 1.2-BENCHMARKING } \\
\hline $\begin{array}{l}\text { Revisão de literatura } \\
\text { (Pesquisa de patentes) }\end{array}$ & $\begin{array}{l}\text {-Conhecimento técnico básico } \\
\text { sobre o tema, } \\
\text {-Conhecimento de } \\
\text { ferramentas de busca, } \\
\text {-Inglês }\end{array}$ & -Capacidade de sintese e análise \\
\hline $\begin{array}{l}\text { Lista periódicos (Lista de } \\
\text { patentes) }\end{array}$ & & -Capacidade de sintese e análise \\
\hline Fichamento & -Redação técnica & -Capacidade de sintese e análise \\
\hline \multicolumn{3}{|l|}{$\begin{array}{l}\text { 1.3-PLANEAAMENTO } \\
\text { DETALHADO DE PROJETO }\end{array}$} \\
\hline $\begin{array}{l}\text { Proposta metodológica de } \\
\text { projeto }\end{array}$ & $\begin{array}{l}\text { "M\&S e Análise: } \\
\text {-Conhecimento e atualização } \\
\text { do tema, } \\
\text {-Redação }\end{array}$ & -Trabalho em equipe \\
\hline $\begin{array}{l}\text { Discussão da metodologia } \\
\text { com corpo técnico do } \\
\text { NEMOS }\end{array}$ & $\begin{array}{l}\text { "Corpo Técnico: } \\
\text {-Conhecimento específico na } \\
\text { área de projeto, } \\
\text {-Atualização sobre a área }\end{array}$ & \begin{tabular}{|l}
-Visão sistêmica, \\
-Clareza, \\
-Comunicação oral, \\
-Organização, \\
-Capacidade de sintese, \\
-Tomada de decisão \\
\end{tabular} \\
\hline
\end{tabular}

Tabela 2 - Competências por Função

\begin{tabular}{|c|c|c|}
\hline \multicolumn{3}{|c|}{ COMEVETENCIAS ONGANEACIONAS } \\
\hline \multicolumn{3}{|c|}{ 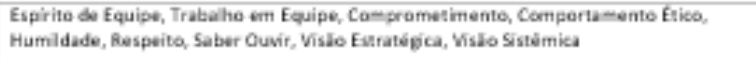 } \\
\hline FUNÇĂO & CORAPETENCIAS TECNECAS & $\begin{array}{l}\text { COMAPETENCIAS } \\
\text { COMAPCATAMENTAIS }\end{array}$ \\
\hline COORDENADOAES & $\begin{array}{l}\text { Conheci-ento eipecifico na ârea } \\
\text { de projeto, } \\
\text {-Atuaízaçào iobre a área }\end{array}$ & 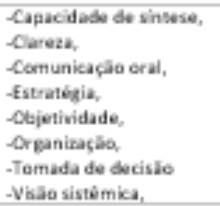 \\
\hline GESTĀO de PROJETOS & $\begin{array}{l}\text {-Técnicas de apresemtaçá, } \\
\text {-frojecs, } \\
\text {-Conheci-ento técnico em gevilo } \\
\text { de projetos }\end{array}$ & 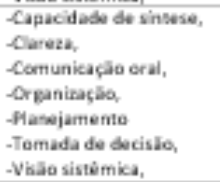 \\
\hline $\begin{array}{l}\text { MODELAGEM E } \\
\text { SIMULAÇ̄o }\end{array}$ & 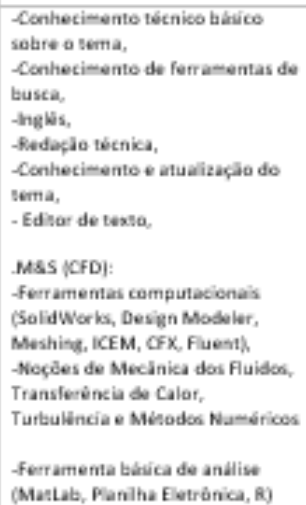 & 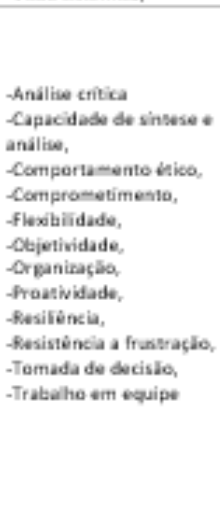 \\
\hline ANÉLLSE & 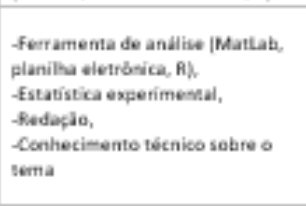 & 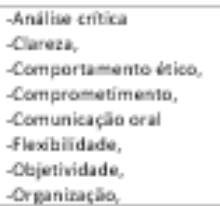 \\
\hline
\end{tabular}




\section{* Seleção de Pessoas: Entrevista Comportamental}

Como ferramenta para a realização do processo seletivo, foi estabelecido um modelo de entrevista comportamental com perguntas situacionais, a qual se baseia em experiências vividas pelos candidatos ao invés de perguntas hipotéticas, o que facilita a identificação do uso das competências em diferentes situações. Para isso, o avaliador deverá induzir o candidato a descrever a situação, a ação desenvolvida e a consequência para cada pergunta. É importante salientar ainda, que as competências técnicas serão observadas durante os cursos oferecidos pelo NEMOS, através de exercícios práticos.

\section{* Medição das Competências: Avaliação de Desempenho}

Consiste em um formulário, no qual estão presentes perguntas relacionadas às competências gerais e específicas da função, através do qual cada membro se avalia e avalia seus colegas de equipe, atribuindo notas de 1 a 5 , além de possuir um campo que lhes permitam indicar em que o avaliado se destacou ou em que pode melhorar.

As respostas dos formulários serão todas compiladas em uma planilha do MS Excel, permitindo a criação de gráficos comparando as notas da auto avaliação com as atribuídas pelos colegas de equipe. Isto facilitará a análise das competências que prioritariamente precisarão ser desenvolvidas, além de permitir observar se a visão de cada colaborador acerca de suas competências corrobora com a observada por sua equipe.

\section{CONSIDERAÇÕES FINAIS}

A gestão por competências surge como uma metodologia que permite o desenvolvimento de ferramentas que propiciem potencializar capacidades humanas, através da alocação do perfil certo no lugar certo, e da compreensão de como mobilizar conhecimentos, habilidades e atitudes para agregação de valor à organização.

As ferramentas desenvolvidas por meio deste trabalho, permitirão a formação de equipes com características adequadas ao cargo, o que propiciará maior desenvolvimento do potencial de cada colaborador e, consequentemente, maior desempenho e motivação na realização de suas atividades. Em última análise, contribuirá para a melhoria de seu processo produtivo e para o desenvolvimento do NEMOS como organização.

\section{REFERÊNCIAS}

AMORIM, T. N. G. F.; SILVA, L. B. "Gestão por Competências: Nuances e Peculiaridades", 2011.

DUTRA, J. S. “Gestão de pessoas com base em competências. In: Gestão por competências". São Paulo: Editora Gente, 2001.

DREJER, A.; RIIS, J. O. "Competence development and technology. How learning and technology can be meaningfully integrated?", Technovation, Amsterdam, v.19, n.10, p.631-644, 1999.

FILENGA, D; MOURA, V. F.; RAMA, A. L. F. “Gestão por Competências: Análise Metodológica e Proposição de um Instrumento para Gestão de Pessoas". Rio de Janeiro, 2010.

FLEURY, M. T. L.; FLEURY, A. "Em busca da Competência”, 2001.

FLEURY, A.; FLEURY, M. T. L. "Estratégias empresariais e formação de competências: um quebra-cabeça caleidoscópio da indústria brasileira". São Paulo: Atlas, 2000.

GRAMIGNA, M. R. "Modelo de competências e gestão de talentos". 2. ed. São Paulo: Prentice Hall, 2007.

RABAGLIO, M. O. "Gestão por competências: ferramentas para atração e captação de talentos humanos". Rio de Janeiro: Qualitymark, 2008.

SANDBERG, J. "Understanding human competence at work: an interpretative approach", Academy of Management Journal, New York, v.43, n.1, p.9-25, 2000.

UBEDA, C. L.; SANTOS, F. C. A. "Os principais desafios da gestão de competências humanas em um instituto público de pesquisa”, Gest. Prod., São Carlos, v.15, n.1, p.189-199, 2008. 